Cadernos de Clio, Curitiba, v. 9, nº. 1, 2018

\title{
A LITERATURA ENQUANTO FONTE HISTÓRICA. O EXERCÍCIO DE REENCANTAMENTO DO MUNDO NA CRÍTICA ROMÂNTICA DE VICTOR HUGO EM OS TRABALHADORES DO MAR (1866).
}

\section{LA LITERATURA COMO FUENTE HISTÓRICA. EL EJERCICIO DE REENCANTAMIENTO DEL MUNDO EN LA CRÍTICA ROMÁNTICA DE VICTOR HUGO EM TRABAJADORES DEL MAR (1866).}

Aguinaldo Henrique Garcia de Gouveia ${ }^{1}$

Resumo: O presente trabalho é resultado de um estudo desenvolvido ao longo de um semestre, no ano de 2017, conjuntamente nas disciplinas de Teoria da História III e História Contemporânea I. Partiu da proposta de trabalhar com títulos da literatura do século XIX enquanto fonte histórica, associando-os com conteúdos das disciplinas supracitadas. A obra escolhida foi Os trabalhadores do mar (1866), de Victor Hugo. Trabalhamos, então, com a crítica romântica de Victor Hugo nesse livro, inserindo nosso estudo no leque mais amplo de produções de conhecimento sobre as vertentes de pensamento do século XIX.

Palavras-chave: Victor Hugo; Os trabalhadores do mar; Literatura do século XIX; Romantismo; Teoria do progresso; Racionalidade.

Resumen: El presente trabajo es el resultado de un estudio desarrollado durante un semestre, en 2017, conjuntamente en las disciplinas de la Teoría de la Historia III y la Historia Contemporánea I. Partió de la propuesta de trabajar con títulos de la literatura del siglo XIX como fuente histórica, asociando ellos con contenidos de las disciplinas anteriores. La obra elegida fue Trabajadores del mar (1866), de Victor Hugo. Luego trabajamos con la crítica romántica de Victor Hugo en este libro, insertando nuestro estúdio

${ }^{1}$ Graduado no curso de História (Licenciatura e Bacharelado) da Universidade Federal do Paraná. 
en la gama más amplia de producciones de conocimiento sobre los hilos de pensamiento del siglo XIX.

Palabras-clave: Victor Hugo; Trabajadores del mar; Literatura del siglo XIX; Romanticismo; Teoría del progreso; Racionalidad.

\section{Introdução}

Hoje, nos meios de produção historiográficos, é fortemente sabido que a escrita da história é um permanente e intenso processo, sujeito a constantes modificações. As fontes utilizadas e os objetos de estudo talvez sejam os grandes exemplos dessa dinâmica. Sujeitos e grupos por tanto tempo ignorados hoje ganham destaque, assim como documentos antes ignorados passam a receber atenção. Da mesma forma, novas perspectivas ganham destaque sobre diferentes questões. É verdade que esse "novo" panorama já vem sendo construído desde as primeiras décadas do século XX. A utilização da literatura enquanto fonte histórica se insere nesse panorama. Tendo isso em mente, nossa proposta aqui almeja, inicialmente, apenas contribuir com mais um pequeno capítulo nesse vasto panorama que abrange os trabalhos com a literatura enquanto fonte histórica.

Importante destacar que a literatura enquanto "transfiguração da realidade" (FERREIRA, 2009: 75) nos fornece uma variedade quase infinita de interpretações, de novas visões, de possibilidades de trabalho, de elementos subjetivos, quase sempre não possíveis de serem abordados em outras fontes.

Antônio Celso Ferreira, em seu texto "A fonte fecunda”, no qual aborda as particularidades da literatura enquanto fonte histórica e dos procedimentos metodológicos necessários, sintetiza bem o que estamos falando aqui: 
A historiografia levou algum tempo para admitir que a literatura pudesse contribuir para o conhecimento das experiências individuais e coletivas de homens e mulheres no tempo. Foi preciso compreender que a história também comportava dimensões subjetivas, imaginárias, oníricas e ficcionais, tão importantes quanto os acontecimentos políticos, sociais e econômicos. Afinal, que outras fontes a não ser as artísticas, dentre as quais sobressai a literatura, deixariam registros tão preciosos e plurissignificativos desse universo humano recôndito, frequentemente recalcado noutros documentos (FERREIRA, 2009: 83-84).

Por fim, é importante ressaltar que, a despeito de todas as suas particularidades, a literatura enquanto fonte histórica deve ser tratada como todos os outros tipos de documentos, ou seja, criticamente, pois ela, assim como eles, não é detentora da verdade e, por isso, sempre que possível, deve ser confrontada com outros documentos, estabelecendo-se entre eles uma relação dialógica.

Nosso trabalho, contudo, se apresenta como um primeiro passo de um estudo que pode vir a ser muito maior e, assim, se expandir e realizar todas as etapas metodológicas necessárias. Tendo isso em mente, deixamos claro que nosso objetivo aqui é realizar uma primeira análise da fonte. Portanto, não realizaremos a tão necessária análise dialógica.

Trabalharemos aqui com o livro do escritor francês Victor Hugo, Os trabalhadores do mar, de 1866. Este trabalho é resultado de um exercício desenvolvido ao longo de um semestre que visava abordar a literatura 
Cadernos de Clio, Curitiba, v. 9, nº 1, 2018

enquanto fonte histórica, estabelecendo relações com aspectos teóricos da historiografia e vertentes de pensamento do século XIX. Dito isso, nosso objetivo aqui, de modo mais amplo, é analisar uma obra literária enquanto fonte histórica, inserindo-a nas produções de conhecimento mais amplas sobre os aspectos teóricos da historiografia e das particularidades dos modos de pensar no século XIX.

Devido às limitações que se impõem, estabelecemos como foco a questão da tensão entre a obra e o contexto no qual ela se insere acerca do ideal de progresso, especificamente sobre a racionalidade constituinte desse ideal, característicos daquele século XIX europeu. Para tanto, partiremos do trabalho de Paolo Rossi acerca da teoria do progresso. A partir disso, trabalharemos com a hipótese de que em Os trabalhadores do mar há elementos que podem ser acrescentados ou que pelo menos estão de acordo com a tese de Rossi de que a racionalidade e a teoria do progresso não eram a episteme absoluta no século XIX. Devemos, antes disso, dedicar algumas palavras ao autor e a obra.

\section{Victor-Marie Hugo e Os trabalhadores do mar (1866)}

Filho de um general de Napoleão e de uma defensora da monarquia de origens inglesas, inserido na sociedade aristocrática francesa do século XIX, Victor-Marie Hugo, nascido em 1802 e falecido em 1885, é, certamente, um dos maiores e mais conhecidos nomes da literatura mundial. Teve sua vida marcada, para além da literatura, pelas contradições e ambivalências, assim como pela disputa pessoal, embora em certos 
Cadernos de Clio, Curitiba, v. 9, nº 1, 2018

momentos nem tão concreta, com Luís Napoleão (ROBB, 2000). Segundo Graham Robb (2000:7), autor de sua biografia:

Para onde quer que se olhe, no século XIX, vê-se um Victor Hugo - e cada um deles acompanhado de sua contradição: a angelical criança prodígio dos primeiros românticos e o satânico 'Átila da língua francesa'; o monarquista militante e o socialista revolucionário; o símbolo de uma aristocracia corrupta e defensor dos misérables; o repressor de revoltas e fomentador de distúrbios.

Descrição talvez um pouco exagerada, mas sintomática da complexidade desse importante personagem histórico.

Devido a sua oposição ao Segundo Império - iniciado em 1851-1852, após as movimentações de 1848, e que Karl Marx chamou de farsa (MARX, 2011) - e, mais especificamente, à figura de Luís Napoleão, Victor Hugo passou duas décadas no exílio. Victor Hugo passou a maior parte desse período nas ilhas normandas do Canal da Mancha, entre Inglaterra e França. Foi nesse contexto que escreveu e publicou $O s$ trabalhadores do mar (1866). As semelhanças entre a vida do autor no período e os elementos de seu livro levantam a hipótese de que seja uma obra com teor autobiográfico. No entanto, esse é um aspecto sobre o qual não nos debruçaremos aqui.

Apesar dessa importância histórica, Os trabalhadores do mar é uma obra muito menos conhecida do que seus dois romances mais famosos, $O$ corcunda de Notre-Dame (1831) e Os miseráveis (1862). 
Cadernos de Clio, Curitiba, v. 9, nº 1, 2018

A trama do livro se passa, assim como a vida do autor no período, nas ilhas normandas. Destacam-se as ilhas de Guernesey e Saint-Malo. A história gira em torno de três personagens principais: Gilliat, Déruchett e Lethierry. Poderíamos ainda acrescentar a máquina a vapor, Durande, pela importância que possui na história. Lethierry é um antigo trabalhador do mar que possui duas grandes paixões na vida, sua máquina a vapor, Durande, e sua sobrinha/filha Déruchett que, embora seja uma das personagens principais, está presa aos padrões da época de construção de personagens femininas, não possuindo, portanto, maiores desenvolvimentos. Por fim, Gilliat, um homem solitário e mal visto por ser associado a crenças populares negativas.

A história se desenvolve apresentando essas personagens, assim como outras secundárias. Tem sempre o oceano e a natureza como elementos permeadores; quase onipresentes. A verdadeira trama é proporcionada pela aventura de Gilliat para salvar a Durande, encalhada após um suposto acidente. Ao mesmo tempo desenvolve-se a história de amor entre Gilliat e Déruchett, que acaba de maneira inesperada. A obra, enfim, mostra a constante relação e luta entre homem e natureza.

\section{A ideia de progresso e a (crítica da) razão}

Paolo Rossi, em seu livro Naufrágios sem espectador: a ideia de progresso (ROSSI, 2000), nos apresenta uma importante discussão acerca desse conceito. $\mathrm{O}$ autor desenvolve uma análise do processo de construção da "teoria do progresso" (ROSSI, 2000: 114), que teria se articulado e se fortalecido em finais do século XVIII. Essa teoria estaria pautada, dentre 
outros pensadores, nos trabalhos de Kant, Hegel e Comte. Teria como premissa central a ideia de que as sociedades e, de modo geral, a História, estariam em constante progresso, um avanço e melhoramento rumo a um estágio ideal.

Rossi, por fim, destaca um dos elementos constituintes, ou seja, basilar, do ideal de progresso, e de todo o período do século XIX, tido como o século do positivismo, do progresso, e da razão, sendo, pois, justamente, este último aspecto o elemento basilar destacado. Dessa forma, inserido no século da teoria do progresso, a racionalidade seria um dos elementos centrais e definidores de toda aquela dinâmica intelectual e social.

Em sua História das ideias politicas (CHÂTELET; DUHAMEL; PISIER-KOUCHNER, 1990), os autores, ao abordarem os pensamentos filosóficos do período moderno, mais precisamente sobre os pensadores desse período afirmam que "sua atividade pertence ao terreno do conhecimento. Ora, o que ele conhece na época atual é a comunidade humana organizada como comunidade de trabalho: seu 'sagrado' é a dominação da natureza, é a razão calculadora, materialista e mecanicista" (CHÂTELET; DUHAMEL; PISIER-KOUCHNER, 1990: 331). Fornecem, portanto, uma boa definição do conceito de razão naquele contexto ao relacioná-la com os princípios modernos citados, fortemente baseados nas mudanças promovidas naquela sociedade que se engendrava na Revolução Industrial. Em outro momento, ao abordarem o Estado Nação do período, os autores afirmam ainda que 
essa exaltação da Nação como substância da vida coletiva inscreve-se facilmente na corrente de pensamento positivista e evolucionista, dominante nessa segunda metade do século XIX; tal corrente apela para a Razão e para as virtudes clássicas, desconfiando do romantismo, que conduziria a excessos (CHÂTELET; DUHAMEL; PISIER-KOUCHNER, 1990: 101).

Aqui, a definição de razão à qual nos referimos ganha novas nuances, acrescentando-se o elemento opositor do romantismo. Esse romantismo, como veremos, é caracterizado, dentre outros fatores, pela retomada de elementos do passado, destacando-se os místicos, espirituais e subjetivos. Foram justamente esses elementos que passaram a ser considerados como não racionais por essa razão que se propunham dominante, pois não se encaixavam em seus padrões.

Por fim, é importante deixar claro, conforme consta no Dicionário Básico de Filosofia (JAPIASSÚ; MARCONDES, 2001), ao definir razão e racionalidade, que "do ponto de vista epistemológico e antropológico, questiona-se a universalidade do conceito de racionalidade e os critérios segundo os quais se caracteriza um procedimento ou uma decisão como racionais" (JAPIASSÚ; MARCONDES, 2001: 162). Ou seja, trata-se de um conceito bem determinado e localizado no tempo e no espaço. É, pois, com essa concepção de razão e racionalidade que trabalharemos aqui. Retornemos, então, ao trabalho de Rossi.

Após analisar esse processo Rossi apresenta, então, sua tese. O autor defende que, mesmo no século XIX, quando essa teoria, ou vertente de 
pensamento, já estava fortemente consolidada, sendo esse período, por isso, apontado como o século da razão e do progresso, sendo eles a "fé do nosso século" (ROSSI, 2000: 123), não havia um paradigma ou episteme absoluto. Ou seja, a teoria do progresso não era unânime. Segundo Rossi “não é absolutamente verdade (ou em todo caso não é absolutamente óbvio) que existam a priori históricos e que cada época seja caracterizada por um paradigma dominante. Não é verdade que, assim como cada homem tem um só rosto, então cada época deve ter também sua própria e inconfundível face, sua específica episteme" (ROSSI, 2000: 118). Para fundamentar sua interpretação o autor apresenta diversos nomes que representariam pensamentos diferentes dos tachados como dominantes na época, pautados no progresso e na razão característicos do período:

Para todos aqueles que tomam como boa a definição do Larousse e colocam sob aquela etiqueta toda a 'época do positivismo' é como se aquelas milhares de páginas jamais tivessem sido escritas. Hyppolite Taine, Bénédict Augustin Morel, Henry Maudsley, Cesare Lombroso, Émile Zola, Scipio Sighele, Gabriel Tarde, Gustav Le Bom, para não falar de Sigmund Freud são eliminados da história como presenças incômodas ou insignificantes anomalias (ROSSI, 2000: 123).

Seria possível acrescentar a essa lista muitos outros nomes, como o de Friedrich Nietzsche sua postura crítica acerca da ideia moderna de progresso pautada na denúncia de que tais ideias "[...] impossibilitam a compreensão da vida humana pelo viés efetivamente capaz de ser afirmado 
no âmbito de uma valoração 'extra-moral', destituída de traços metafísicos" (BITTENCOURT, 2011: 94).

Todavia, o nome que realmente queremos acrescentar é o de Victor Hugo. Para tanto, trabalharemos com sua obra Os trabalhadores do mar, de 1866, especialmente no que cabe aos elementos de tensão, presentes nessa obra, que se chocam com os ideais de racionalidade tidos como dominantes naquele século XIX. Focaremos, então, nosso estudo em um elemento central de tensão na obra de Hugo, seu exercício de reencantamento do mundo, frente aos ideais de racionalidade do período.

Antes de abordarmos diretamente essas tensões, no entanto, devemos dedicar algumas palavras a um conceito essencial ao nosso trabalho, o Romantismo, mais especificamente a crítica romântica, de onde provém o conceito de reencantamento do mundo, com o qual trabalharemos.

\section{O Romantismo e a crítica romântica}

No livro Revolta e melancolia. O romantismo na contracorrente da modernidade (LOWY; SAYRE, 2015), Michael Lowy e Robert Sayre buscam definir um conceito e estabelecer tipologias do romantismo. Para isso utilizam um método particular, unindo o dialético e o weberiano:

Portanto, é a partir da teoria das Weltanschauungen e das análises de Lukács e Goldmann que tentaremos formular nosso conceito. Aqui, não se tratara de construir um 'tipo ideal' weberiano (necessariamente fundamentado em uma seleção parcial), mas sim encontrar o conceito - no sentido forte de Bergriff dialético da tradição hegeliano-marxista - que 
possa justificar as contradições do fenômeno e sua diversidade. Isso dito, as duas posturas nos parecem complementares e não contraditórias e teremos a oportunidade - na construção de uma tipologia das formas do romantismo de utilizar o método weberiano (LOWY; SAYRE, 2015: 36).

Os autores estabelecem, então, seis tipos de romantismos: a) restitucionista; b) conservador; c) fascista; d) resignado; e) reformador e f) revolucionário e/ou utópico. Este último, por sua vez, possui cinco tendências distintas: a jacobino-democrática, a populista, a socialista utópico-humanista, a libertária e a marxista. Cada uma dessas tipologias possui uma série de particularidades, contabilizando uma complexidade imensa. Todavia, não trataremos desses elementos aqui. O que objetivamos com essa breve apresentação das tipologias levantadas por Lowy e Sayre é evidenciar a complexidade do romantismo e dos estudos sobre ele, além de localizar melhor nosso trabalho no conhecimento produzido e em quais estudos ele se ampara.

O que nos interessa diretamente aqui é o conceito no qual os autores chegaram, ou seja, o elemento central, a premissa geral, presente em todas as tipologias de romantismo - embora ela se manifeste de formas diferentes em cada um deles. Esse conceito pode ser definido como a crítica à sociedade moderna, definida como a sociedade burguesa, engendrada na Revolução Industrial e na economia de mercado, marcada, por sua vez, pela nostalgia de algum valor do passado. Essa crítica era direcionada especialmente para cinco elementos daquela sociedade: a) o desencantamento do mundo; b) a quantificação do mundo; c) a 
mecanização do mundo; d) a abstração racionalista e e) a dissolução dos vínculos sociais.

Nesse ponto, nos alvos da crítica romântica, especialmente no que se refere ao desencantamento do mundo, voltamos a Victor Hugo e a sua obra Os trabalhadores do mar. O desencantamento do mundo seria a exaltação do racional, valor considerado dominante na "época do positivismo" (ROSSI, 2000: 123), ou seja, no século XIX da era do progresso, em detrimento do místico. Entendemos que em Os trabalhadores do mar encontramos exatamente essa crítica romântica ao desencantamento do mundo, através de um exercício de reencantamento do mundo, ou seja, de um exercício de exaltação desses mesmos elementos relegados como não racionais pelo racionalismo tido como dominante no século XIX.

Para defendermos nosso ponto, antes de apresentarmos nossas interpretações do livro de Victor Hugo, é necessário deixarmos claro uma particularidade da literatura enquanto crítica da sociedade, especialmente da literatura romântica, como em nosso caso. Ainda no livro Revolta e melancolia Lowy e Sayre abordam essa questão afirmando que

nas obras literárias, é raro encontrarmos, por parte do autor, uma denúncia franca e sem ambiguidades dos males da sociedade atual. $\mathrm{O}$ artista transmite seu ponto de vista muito mais pela organização da narrativa, pela sugestão, pela ironia, em uma palavra, por um arsenal de técnicas literárias (LOWY; SAYRE, 2015: 42). 
Pois é justamente dessa forma, nunca objetivamente, que encontramos os elementos de crítica em Os trabalhadores do mar.

\section{$O$ reencantamento do mundo}

Ora, apresentemos, então, nossas interpretações do livro de Victor Hugo. Como já dissemos, entendemos que a crítica romântica presente em Os trabalhadores do mar é direcionada especialmente ao desencantamento do mundo, ou seja, à maior valoração dos elementos racionais - segundo os padrões de racionalidade do século XIX -, o que, consequentemente, relega os elementos místicos e espirituais à marginalidade - essa dinâmica, devemos lembrar, era característica do ideal de progresso, no século XIX, como aponta Rossi. A retomada desses elementos místicos e espirituais, considerados naquele período como não racionais, portanto, seria uma forma de crítica e/ou resistência ao desencantamento do mundo, característico da racionalidade tida como dominante no século XIX.

Vamos nos focar agora, enfim, em alguns dos elementos presentes na obra de Victor Hugo, que contém essa tensão entre a racionalidade característica do século XIX e o exercício de reencantamento do mundo executado pelo autor, que se choca, exatamente, com essa racionalidade.

Segundo Lowy e Sayre, "uma das principais modalidades românticas de reencantamento do mundo é o retorno às tradições religiosas e por vezes místicas, como salienta Weber. A tal ponto, que inúmeros críticos consideram a religião o principal traço do espírito romântico" (LOWY; SAYRE, 2015: 53). Sabemos, todavia, que a retomada e a defesa da 
religião não são elementos comuns aos diversos tipos de romantismos. Afinal, a religião não é o único elemento místico e/ou espiritual que possibilita o reencantamento do mundo:

Mas a religião - em suas formas tradicionais ou manifestações místicas e/ou heréticas - não é o único meio de 'reencantamento' escolhido pelos românticos: eles também se voltam para a magia, as artes esotéricas, a feitiçaria, a alquimia, a astrologia; redescobrem os mitos pagãos ou cristãos, as lendas, os contos de fadas, as narrativas 'góticas'; exploram os reinos ocultos dos sonho e do fantástico - não apenas na literatura e na poesia, mas também na pintura, desde Fussli e Blake até Max Kinger e Max Ernst (LOWY; SAYRE, 2015: 53).

É principalmente nos elementos não relacionados diretamente à religião, ou ao menos não relacionados a suas manifestações tradicionais, como a Igreja, embora também nelas, que se insere o exercício de reencantamento do mundo de Victor Hugo.

Como pode ser percebido em sua biografia, Victor Hugo não era uma pessoa que nutria grandes afetos com a igreja, seja qual fosse. Robb chega a definir Victor Hugo como "paladino do anticlericalismo" (ROBB, 2000: 273), embora destaque que esse é mais um aspecto ambivalente da vida do escritor. Talvez por isso sua postura de reencantamento do mundo tenha ocorrido de maneira fortemente independente da Igreja; embora o mesmo não possa ser dito quanto à religião - compreendida enquanto uma 
série de definições e estruturas de crenças - visto que essa é uma distinção facilmente perceptível na obra do autor.

Em Os trabalhadores do mar, o exercício de reencantamento do mundo ocorre muito mais através de crenças populares, do místico e do oculto, de uma espiritualidade própria, de tradições, da exaltação da natureza.

Diversos são os momentos da obra de Victor Hugo em que podemos notar tais aspectos de reencantamento:

A noite desse dia, das 10 horas em diante, devia ser noite de luar. Todavia, qualquer que fosse a boa aparência da noite, do vento e do mar, nenhum pescador estava disposto a sair nem de Hougue la Perre, nem de Bourdeaux, nem de Houmet Benet, nem de Platon, nem de Port-Grat, nem da baía Vason, nem de Perelle Bay, nem de Pezeris, nem de Tielles, nem da baía dos Santos, nem de Petit Bô, nem de nenhum outro porto ou angra de Guernesey. E isso por uma razão simples: o galo tinha cantado ao meio-dia (HUGO, 2002: 174-175).

Percebe-se nesse trecho como uma crença popular, a respeito do canto de um galo em horário não corriqueiro, pautou todas as ações marítimas de toda uma região. Importante pontuar que esse tipo de postura dos personagens não é exposta de modo depreciativo pelo narrador, mas sim como algo natural e corriqueiro naquele contexto.

Em outro trecho, inserido na labuta de Gilliat, sozinho no mar e acometido pelas maiores dificuldades possíveis, para recuperar a máquina a 
vapor Durande, percebe-se o forte teor espiritual e/ou místico inserido na leitura de mundo:

O inacessível ligado ao inexplicável, eis o céu.

Dessa contemplação solta-se um fenômeno sublime: o crescimento da alma pelo assombro.

O medo sagrado é próprio do homem; a besta ignora esse medo. A inteligência acha nesse terror augusto o seu eclipse e a sua prova.

A sombra é uma: vem daí o seu horror. É, ao mesmo tempo, complexa: vem daí o terror. a sua unidade pesa no espírito e saca-lhe a vontade de resistir (HUGO, 2002: 238).

Victor Hugo trata, ainda, de modo mais direto da religião, ao dizer que

constrange-se-nos à fé. Crer por força, eis o resultado. Mas para estar tranquilo, não basta ter fé. A fé tem uma estranha necessidade de forma. Daí vêm as religiões. Nada tão opressivo como uma crença sem delineamento (HUGO, 2002: 240).

Destaca-se o uso da palavra religiões, no plural, denotando, portanto, um caráter amplo e abrangente da ideia.

Entendemos que há, ainda, outra importante forma de reencantamento do mundo levada a cabo por Victor Hugo, a saber, as constantes ações consideradas não racionais, ou que não se enquadravam nos padrões da racionalidade da época, e os modos como são apresentadas, destacando-se o amor romântico. A relação entre Gilliat e Déruchette, um dos aspectos centrais da obra, é o que melhor fornece esses elementos. 
Talvez o maior e melhor exemplo disso seja a decisão de Gilliat de se lançar ao mar, contrariando todas as probabilidades de sucesso e mesmo de sobrevivência, e se opondo às negações de outros personagens, para salvar a máquina a vapor, Durande, motivado pelo amor que sentia por Déruchette.

O patrão do Shealtiel, que era um antigo piloto, resumiu o pensamento de todos exclamando em alta voz:

- Não! Está acabado. Não existe um homem capaz de ir buscar a máquina!

- Se eu não vou - disse Imbrancam - é que é impossível de ir.

$\mathrm{O}$ patrão de Shealtiel sacudiu a mão esquerda com aquele arrebatamento que exprime a convicção do impossível, e repetiu:

- Se existisse.

Déruchette voltou a cabeça.

- Casava-me com ele.

Houve um silêncio.

Um homem pálido saiu dos meios dos grupos e disse:

- A senhora casava-se com ele, Miss Déruchette?

Era Gilliat.

Entretanto, todos levantaram os olhos. Mess Lethierry endireitou-se. Tinha nos olhos uma luz estranha.

Tirou o boné e lançou ao chão, depois olhou solenemente para a frente sem ver pessoa alguma e disse:

- Déruchette casava-se com esse homem. Dou minha palavra de honra a Deus (HUGO, 2002: 174).

Embora a ação de Gilliat tenha como objetivo salvar um símbolo do progresso, a máquina a vapor, não se trata de um sacrifício por esse símbolo ou de uma ação que simbolize a exaltação desse símbolo. 
Entendemos que o elemento que realmente deve ser destacado aqui é a motivação de Gilliat, ou seja, seu amor por Déruchett. Um amor romântico que vai na contramão dos ideais racionalistas do século XIX. Lembremos sempre que esses ideais racionalistas e o ideal de progresso foram engendrados numa sociedade que via o florescimento e rápida concretização do capitalismo e da Revolução Industrial, logo uma atitude que fosse racional, seguindo essas bases, estaria muito mais preocupada com a máquina a vapor, símbolo do progresso e industrialização, questões financeiras e demais elementos concernentes. Dessa forma, a atitude e motivação de Gilliat, seriam consideradas não racionais. Por fim, o tratamento que Victor Hugo oferece a Gilliat concretiza a postura de exaltação desses ideais tidos como não racionais naquele período, pois o autor constrói esse personagem como heróico e digno de admiração.

A narrativa passa, então, a ser grandemente centralizada nas ações de Gilliat, no estudo de seu personagem, na posterior relação entre ele e Déruchett. Compreensível, dessa forma, que o amor romântico passe a ser elemento de destaque na história. O seguinte trecho, já mais ao final do livro, exemplifica melhor o que é esse amor romântico:

Estar perto dela, era acaso possível? Ouvi-la respirar; respirava pois! Então os astros respiram. Gilliat estremecia. Era o mais miserável e o mais inebriado dos homens. Não sabia que fazer. O delírio de vê-la esmagava-o. Pois quê! Era ela quem ali estava, era ele que ali estava! As suas ideias, deslumbradas e fixas, paravam naquela criatura como se fosse um rubi. Contemplava aquela nuca e aqueles cabelos. Gilliat nem mesmo pensava que tudo aquilo lhe pertencia, que em pouco 
tempo, talvez amanha, ele teria o direito de tirar-lhe aquela coifa e deslaçar aquela fita. Sonhar até esse ponto era um excesso de audácia que ele não poderia conceber um momento. Tocar com o pensamento e quase tocar com a mao. $\mathrm{O}$ amor era para Gilliat como mel para urso, o sonho exímio e delicado. Pensava confusamente. Não sabia o que tinha.

O rouxinol cantava. Ele sentia-se expirar (HUGO, 2002: 326-327).

Percebe-se, com o trecho supracitado, mais claramente, o que é o amor romântico e como ele se afasta dos ideais de racionalidade do ideal de progresso do século XIX.

A retomada de mitos e crenças do passado, que demonstram o caráter nostálgico do autor - outro importante elemento do romantismo -, também possui destaque em Os trabalhadores do mar, especialmente da cultura grega:

De súbito ouve-se um grande murmúrio confuso. Há uma espécie de diálogo misterioso no ar.

Não se vê coisa alguma.

A extensão fica impassível.

Entretanto, o rumor cresce, engrossa, eleva-se. Acentua-se o diálogo.

Há alguém por trás do horizonte.

Pessoa terrível essa, é o vento.

O vento, isto é, a população de titãs que chamamos Tufões. Imensa plebe da sombra.

A Índia chamava-os Morouts, a Judéia Querubins, a Grécia Aquilões. São os invisíveis pássaros ferozes do infinito. Esses Bóreas precipitam-se (HUGO, 2002: 258). : 
Percebe-se, novamente, a utilização de elementos místicos, agora nomeados e retomados de tradições antigas, na leitura de mundo, da Natureza.

Em muitos outros momentos da narrativa diversos elementos de culturas Antigas são retomados, como a Hidra, Éolo, Ceto, os ciclopes, sempre representados positivamente e buscando acrescentar à narrativa maior compreensibilidade e significado. Mesmo autores da Antiguidade são retomados, da mesma forma que os elementos anteriores, como, por exemplo, Homero.

Esse terceiro elemento expõe mais um exemplo de reencantamento do mundo, ao trazer fatores de tradições e subjetividades, crenças, enfim, de um passado distante. Esse fator, inclusive, pode ser interpretado como a característica do romantismo de retomada de elementos do passado.

\section{Considerações finais}

Esperamos, primeiramente, ter cumprido com o objetivo de demonstrar - e praticar - a importância da literatura enquanto fonte histórica. Trazendo um estudo que não se atenta a buscar na literatura ecos de aspectos políticos, econômicos ou propriamente da convivência social, mas sim, trabalhando com as particularidades das formas de pensar de determinado contexto, e priorizando o choque com os elementos característicos do contexto no qual se insere.

Destacamos a crítica na obra de Victor Hugo à sociedade moderna, especialmente direcionada ao desencantamento do mundo e à 
racionalização, característicos da racionalidade constituinte do ideal de progresso no século XIX. Como também demonstramos, ambos são alvos da crítica romântica. É verdade que outros tantos elementos que compõem o romantismo não estão presentes em Os trabalhadores do mar. Todavia, como defendido por Lowy e Sayre, o romantismo pode se manifestar de diversas formas e, dificilmente, encontra-se, em um único autor, tampouco numa única obra, todas as características do romantismo. Com isso, caso não se queira cravar que esta obra de Victor Hugo é romântica e exerce essa crítica, é inegável que o autor lança mão de alguns elementos do romantismo, especialmente de sua crítica a modernidade, especificamente sobre a racionalidade que marginaliza elementos espirituais, místicos, religiosos, que passam, assim, a serem considerados não racionais.

Outra conclusão que devemos destacar é que, apesar de termos nos focado em elementos bem determinados da obra, devemos deixar bem claro que ela não se trata de um projeto monolítico, sem nuances e/ou contradições aparentes. Ao nos focarmos apenas na crítica da racionalidade executada na obra é possível que se passe a impressão de que essa obra é, simplesmente, uma crítica à modernidade, ao ideal de progresso e a tudo o que é apresentado como dominante do século XIX. Todavia, essa também é uma obra de seu tempo, e possui, evidentemente, inúmeras nuances, como o elemento fortemente presente nela da luta entre homem e Natureza, muitas vezes associado como elemento constituinte desse mesmo século XIX que exalta a racionalidade que a obra critica. 
Cadernos de Clio, Curitiba, v. 9, nº 1, 2018

Por fim, pudemos perceber a força da tese de Rossi, ou seja, de que não há uma episteme absoluta em determinado período, no caso, a teoria do progresso e, especificamente, a razão, ou melhor, a racionalidade do século XIX, para a qual esperamos ter oferecido nossa singela contribuição.

\section{Bibliografia}

BITTENCOURT, Renato Nunes. As falácias da ideia de progresso segundo "Nietzsche". In. Acta Scientiarum. Human and Social Sciences. Maringá, v. 33, n. 1, pp. 81-96, 2011.

CHÂTELET, François; DUHAMEL, Olivier; PISIER-KOUCHNER, Evelyne. História das Idéias POLÍTICAS. [Trad. Carlos Nelson Coutinho] 2a ed. Rio de Janeiro: Jorge Zahar Editora, 1990.

CIOCCARI, Marta. Entre o mar e o rochedo: uma análise antropológica sobre as noções de natureza em Os trabalhadores do mar de Victor Hugo. In: Cadernos de campo, São Paulo, n. 18, pp. 29-46, 2009.

FERREIRA, Antonio Celso. A fonte fecunda. In: PINSKY, Carla Bassanezi; LUCA, Tania Regina de (orgs). O historiador e suas fontes. São Paulo: Contexto, 2009.

GARDINER, Patrick. Teorias da História. Lisboa: Fund. Calouste Gulbenkian, 1969.

HUGO, Victor. Os trabalhadores do mar. São Paulo: Nova Cultural, 2002.

JAPIASSÚ, Hilton; MARCONDES, Danilo. Dicionário básico de filosofia. Jorge Zahar: Rio de Janeiro, 2001. 
Cadernos de Clio, Curitiba, v. 9, nº 1, 2018

LOWY, Michael; SAYRE, Robert. Revolta e melancolia: o romantismo na contracorrente da modernidade. São Paulo: Boitempo, 2015.

MARX, Karl. O 18 Brumário de Luís Bonaparte. São Paulo: Boitempo, 2011.

ROBB, Graham. Victor Hugo. Uma biografia. Rio de Janeiro: Record, 2000.

ROSSI, Paolo. Naufrágios sem espectador: a ideia de progresso. São Paulo: Ed. UNESP, 2000.

VEDRINE, Hélène. As filosofias da história: decadência ou crise?. Rio de Janeiro: Zahar, 1977.

Recebido em: 01/09/2019 Aceito em: 15/07/2020 